\title{
Microencapsulamento de hidrolisados de caseína em lipoesferas para mascarar o sabor amargo: avaliação físico-química e sensorial
}

\author{
Cristiane Márcia da Silva Barbosa', Harriman Aley Morais', Daniella Cristine Fialho Lopes', \\ Herman Sander Mansur ${ }^{2}$, Mônica Cristina de Oliveira ${ }^{3}$, Marialice Pinto Coelho Silvestre ${ }^{1 *}$
}

\author{
${ }^{1}$ Departamento de Alimentos, Faculdade de Farmácia, Universidade Federal de Minas Gerais, ${ }^{2}$ Departamento de \\ Engenharia Metalúrgica e de Materiais, Escola de Engenharia, Universidade Federal de Minas Gerais, ${ }^{3}$ Departamento \\ de Produtos Farmacêuticos, Laboratório de Farmacotécnica, Universidade Federal de Minas Gerais
}

*Correspondência: M. P. C. Silvestre

Depto. de Alimentos

Laboratório de Bromatologia

Faculdade de Farmácia - UFMG

Av. Olegário Maciel, 2360 - Sala 320

Belo Horizonte - MG CEP 30180-112

E-mail: malice@farmacia.ufmg.br
A hidrólise enzimática de proteínas pode levar ao desenvolvimento de sabor amargo, associado à liberação de grupos hidrofóbicos. Neste trabalho, desenvolveu-se uma nova metodologia, baseada no encapsulamento em lipoesferas, para mascarar o sabor amargo de hidrolisados de caseina obtidos pela ação da papaína. Além disso, utilizou-se a espectrofotometria derivada segunda (EDS), como método de determinação da taxa de encapsulamento de hidrolisados enzimáticos de proteinas, e as amostras analisadas apresentaram valores em torno de $66 \%$. Este microencapsulamento mostrou ser uma tecnologia eficiente para reduzir a hidrofobicidade e o sabor amargo de hidrolisados de caseína. A análise por microscopia eletrônica de varredura revelou a morfologia esférica das microcápsulas e a medida da oxidação lipídica mostrou boa estabilidade química por período de até 60 dias.
Unitermos:

- Hidrolisados protéicos

- Sabor amargo

- Encapsulamento em

lipoesferas

- Microscopia eletrônica

- Espectrofotometria derivada segunda

- Oxidação lipídica

\section{INTRODUÇÃO}

A introdução na dieta de hidrolisados enzimáticos ricos em pequenos peptídeos pode ser importante, no sentido de propiciar melhor utilização das proteínas, principalmente em determinadas situações como a que ocorre em indivíduos com intolerância à proteína ou em portadores de deficiência enzimática (Chataud et al., 1988; GonzálesTello et al., 1994). Com esse objetivo, os hidrolisados protéicos têm sido utilizados, especialmente nos países desenvolvidos, na fabricação de alimentos especiais para diversos grupos, tais como os recém-nascidos prematuros, as crianças com diarréia, gastroenterite, má-absorção, fenilcetonúria e, ainda, para pessoas com alergia a proteínas, visto que o decréscimo no tamanho dos peptídeos tem relação direta com a diminuição da imunogenicidade (Smithers, Bradford, 1991; Freitas et al., 1993; Boza et al., 1995; Synowiecki et al., 1996). Além disso, estes preparados enzimáticos podem ser úteis na suplementação dietética de idosos, na nutrição de esportistas e, também, em dietas para controle de peso (FrFKjaer, 1994).

Uma desvantagem encontrada no processo de hidrólise enzimática, e que representa um dos principais obstáculos na aplicação generalizada dos hidrolisados, constitui o desenvolvimento de gosto amargo no decorrer da catálise, o qual parece estar relacionado à liberação de 
grupos hidrofóbicos, que se encontravam no interior das moléculas protéicas (Adler-Nissen, 1981; Minagawa et al., 1989; Sgarbieri, 1996). Muitas técnicas têm sido sugeridas para reduzir ou mascarar o amargor em hidrolisados, incluindo a aplicação da cromatografia de interação hidrofóbica; o tratamento com carbono ativado; a hidrólise com exopeptidases; a formação de plasteína e a extração com solventes orgânicos (Lin et al., 1997; Stevenson et al., 1998; Kristinsson, Rasco, 2000). Entretanto, estes métodos apresentam alguns inconvenientes, tais como a adsorção de aminoácidos hidrofóbicos, por exemplo, fenilalanina e triptofano, que são essenciais; a produção excessiva de aminoácidos livres, elevando a osmolaridade do produto; a reversibilidade da reação e o baixo rendimento juntamente com o problema da toxicidade, respectivamente (Pedersen, 1994; Stevenson et al., 1998). Uma nova maneira de se reduzir ou eliminar o contato destes grupos hidrofóbicos com as papilas gustativas poderia ser através do emprego da tecnologia de encapsulamento dos hidrolisados protéicos. Vários sistemas têm sido utilizados com esta finalidade, especialmente na indústria farmacêutica, visando à melhoria da estabilidade, liberação prolongada do princípio ativo e, ainda, direcionamento do princípio ativo no seu sítio de ação. Por outro lado, com relação à indústria alimentícia poucos trabalhos foram publicados a respeito do uso da tecnologia de encapsulamento, sendo que nestes casos o sistema testado foi o de lipossomas (Kim, Baianu, 1991; Shahidi, Han, 1993; Benita, 1996). Até o momento, nenhum dado foi encontrado na literatura sobre o emprego de lipoesferas no encapsulamento de alimentos.

Alguns autores (Domb, 1993a,b; Benita, 1996, Utreja et al., 1999) relataram a superioridade das lipoesferas como sistemas de encapsulamento frente a outros, a qual estaria relacionada a alguns fatores, tais como melhor estabilidade, uso de ingredientes de baixo custo, fácil preparo em grande escala, alta dispersibilidade em meios aquosos e elevada taxa de encapsulamento de substâncias hidrofóbicas. Considerando estas vantagens, seria interessante testar seu emprego no encapsulamento de produtos alimentícios, tais como os hidrolisados protéicos para fins dietéticos.

À vista do exposto, o presente trabalho teve como objetivo desenvolver uma nova tecnologia para o mascaramento do sabor amargo de hidrolisados de caseína, obtidos pela ação da papaína, baseada no encapsulamento em lipoesferas. Para isto, a espectrofotometria derivada segunda (EDS) foi utilizada, pela primeira vez, como método de determinação da taxa de encapsulamento de hidrolisados enzimáticos de proteínas.

\section{MATERIAL E MÉTODOS}

\section{Material}

A papaína foi gentilmente doada pela BIOBRÁS (Montes Claros, Brasil). A caseína bovina (C7078) e o sulfonato de 8-anilino-1-naftaleno (ANS, A5144) foram adquiridos da Sigma Chemical (St. Louis, MO, EUA). Fosfatidilcolina de soja (792018-1) foi gentilmente doada pela Lipoid GmBh (Darmstad, Alemanha). O ácido esteárico foi adquirido da Galena Química e Farmacêutica Ltda (Belo Horizonte, MG, Brasil). O ácido tiobarbitúrico (1.08180) foi adquirido da Merck (Darmstad, Alemanha). Todos os demais reagentes empregados neste trabalho eram de grau analítico.

\section{Métodos}

\section{Amostras}

Para este trabalho, foram utilizados três hidrolisados de caseína, obtidos pela ação da papaína, que apresentaram o melhor perfil peptídico para dietas especiais, em trabalhos anteriormente realizados (dados do autor ainda não publicados), e que aqui foram denominados de $\mathrm{H} 1, \mathrm{H} 2$ e H3. As condições empregadas para o preparo destes hidrolisados estão apresentadas na Tabela I.

TABELA I - Parâmetros hidrolíticos empregados no preparo dos hidrolisados de caseína pela papaína

\begin{tabular}{ccccc}
\hline Hidrolisados & $\begin{array}{c}\text { Temperatura } \\
\left({ }^{\circ} \mathrm{C}\right)\end{array}$ & $\mathrm{pH}$ & $\begin{array}{c}\mathrm{E}: \mathrm{S} \\
(\%)\end{array}$ & $\begin{array}{c}\text { Tempo } \\
(\mathrm{h})\end{array}$ \\
\hline $\mathrm{H} 1$ & 37 & 7,5 & 2 & 5 \\
$\mathrm{H} 2$ & 40 & 7,5 & 4 & 5 \\
$\mathrm{H} 3$ & 60 & 7,5 & 4 & 5 \\
\hline
\end{tabular}

$\mathrm{E}: \mathrm{S}=$ relação enzima:substrato

\section{Encapsulamento em lipoesferas}

O método de fusão, como descrito por Domb (1993 b), foi empregado para o preparo das lipoesferas contendo hidrolisados de caseína (lipoesferas integrais $-L I$ ). Basicamente, $320 \mathrm{mg}$ de hidrolisado de caseína foram adicionados a $630 \mathrm{mg}$ de ácido esteárico, previamente fundido à temperatura de $70^{\circ} \mathrm{C}$ (banho ultratermostático FANEM UNITEMP, modelo 116B, São Paulo, Brasil). A essa matriz adicionaram $100 \mathrm{~mL}$ de solução de 
fosfatidilcolina de soja $1 \mathrm{~g} \%(\mathrm{p} / \mathrm{v})$ em tampão fosfato 0,1 mol/L, pH 7,4, na mesma temperatura de fusão do ácido esteárico. A mistura resultante foi homogeneizada por cerca de 3 min a $9500 \mathrm{rpm}$ (homogeneizador Ultra-Turrax IKA Labortechnik, modelo IKA T25 Basic, Staufen, Alemanha), até a formação de uma emulsão. Em seguida, a formulação foi rapidamente resfriada, até aproximadamente $20^{\circ} \mathrm{C}$, mediante a imersão em banho de gelo e acetona, sob agitação. Para o preparo das lipoesferas brancas $(L B)$, seguiu-se o mesmo procedimento, porém sem adição de hidrolisados de caseína. As $L I$ e $L B$ assim preparadas foram, então, liofilizadas (temperatura de $-45^{\circ} \mathrm{C}$, vácuo de $90 \times 10^{-3} \mathrm{mBar}$, por $48 \mathrm{~h}$, liofilizador Free Zone, modelo 77500, Labconco, Kansas City, MI, EUA) e mantidas sob refrigeração a $4{ }^{\circ} \mathrm{C}$, até o momento de utilização.

\section{Caracterização das lipoesferas}

A forma e o tamanho das lipoesferas $(L I)$ foram determinados através da microscopia eletrônica de varredura (Jeol modelo JSM 5410 com microsonda EDX acoplado, MA, EUA). As amostras liofilizadas de $L I$ foram reconstituídas em água destilada e adicionadas de solução de glutaraldeído a 5\% (v/v) e, então, fixadas sobre membrana de celulose de $0,20 \mu \mathrm{m}$ de porosidade e $1,3 \mathrm{~cm}$ de diâmetro (Sartorius, Alemanha).

\section{Determinação da taxa de encapsulamento}

Para a determinação da taxa de encapsulamento de hidrolisados de caseína, foi desenvolvida metodologia baseada na EDS. Foram feitas leituras de espectros de absorbância, na faixa de 250 a $300 \mathrm{~nm}$ (espectrofotômetro CECIL modelo CE2041, Buck Scientific, Inglaterra), de soluções de $L I$, com concentrações de hidrolisados de caseína variando de 69,0 a $161,0 \mathrm{mg} / \mathrm{mL}$, obtidas através de diluições sucessivas de uma solução estoque de $L I$, com concentração de hidrolisados de $138 \mathrm{mg} \%(\mathrm{p} / \mathrm{v})$. As lipoesferas contendo o hidrolisado foram dissolvidas em $n$-propanol (1:2), e posteriormente aquecidas em banho maria, $90^{\circ} \mathrm{C}$. Como branco, foram utilizadas soluções de $L B$, contendo as mesmas concentrações de lípides encontradas na $L I$. Soluções de $L B$ foram tratadas como descrito previamente para $L I$. Para traçar os espectros de derivada segunda, um computador contendo software GRAMSUV (Galactic Industries Corporation, Salem, NH, EUA) foi acoplado ao espectrofotômetro. A título de ilustração, os espectros de absorbância e de derivada segunda da $L I$ contendo o hidrolisado $\mathrm{H} 1$, na concentração de $0,161 \mathrm{mg} /$ $\mathrm{mL}$ estão apresentados na Figura 1.

Para a escolha da curva padrão, foram traçados quatro tipos de curva, dois para o pico negativo "a" e dois para o "b" (Figura 1), empregando suas respectivas áreas ou alturas, em função da concentração do hidrolisado nas lipoesferas integrais $(H t)$.

A taxa de encapsulamento do hidrolisado de caseína foi determinada indiretamente. Inicialmente, a $L I$ foi purificada, através de três centrifugações consecutivas a $14000 \mathrm{rpm}$, por $90 \mathrm{~min}$, a $4{ }^{\circ} \mathrm{C}$ (ultracentrífuga Hitachi modelo himac CR21, Japão). Entre cada centrifugação, o sobrenadante foi retirado e reservado, sendo o precipitado reconstituído com igual volume de tampão fosfato $0,1 \mathrm{~mol} / \mathrm{L}, \mathrm{pH} 7,4$. Os três sobrenadantes foram agrupa-
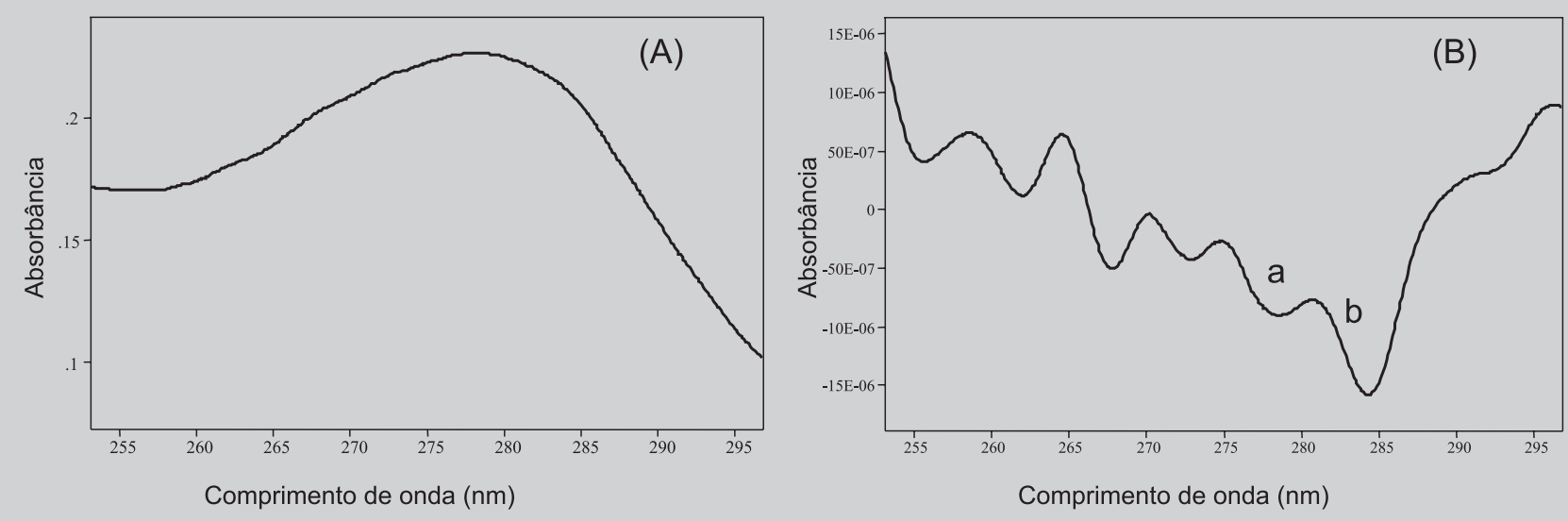

FIGURA 1 - Espectros de absorbância (A) e de derivada segunda (B) das lipoesferas integrais contendo hidrolisado H1. $a=$ pico negativo da tirosina e triptofano; $b=$ pico negativo do triptofano. 
dos, anotando-se o volume total para cada $L I$. Deste total, tomaram-se $300 \mu \mathrm{L}$ e fez-se a leitura do espectro de absorbância e de derivada segunda, entre 250 e $300 \mathrm{~nm}$, calculando-se a concentração de hidrolisado no sobrenadante $(H s)$ a partir da curva padrão.

Posteriormente, determinou-se a taxa de encapsulamento $(T E)$ pela seguinte equação:

$$
T E(\%)=\frac{H e}{H t} \times 100
$$

na qual $H e=H t$ - $H s$, e corresponde à concentração de hidrolisado encapsulado.

\section{Determinação de hidrofobicidade}

A determinação da hidrofobicidade foi realizada para $L I, L B$ e soluções de hidrolisados puros $(H p)$, segundo metodologia descrita por Boatright e Hettiarachchy (1995). Soluções de $H p$ foram preparadas em tampão fosfato de potássio $0,01 \mathrm{~mol} / \mathrm{L}, \mathrm{pH} 7,4$, em concentrações variando de 5 a $9 \mathrm{mg} \%$ (p/v). Foram feitas soluções de $L I$, contendo as mesmas concentrações de hidrolisados de $H p$, e soluções de $L B$, contendo as mesmas concentrações de lípides encontradas na $L I$.

Volume de $30 \mathrm{~mL}$ de solução de ANS, preparada em tampão fosfato $0,1 \mathrm{~mol} / \mathrm{L}$ (pH 7,0), foi adicionado a $6 \mathrm{~mL}$ destas soluções. A leitura da fluorescência foi feita no $1_{\text {excitação }}=374 \mathrm{~nm} \mathrm{e} 1_{\text {emissão }}=485 \mathrm{~nm}$ (fluorímetro digital Turner, modelo 450, Dubuque, IA, EUA). Para o cálculo da hidrofobicidade foram traçadas três tipos de curvas de fluorescência: para os $H p$, para as $L I$ e para as $L B$, em função da concentração dos hidrolisados em $H p$ e $H t$ e de lípides, respectivamente. A inclinação destas curvas corresponde ao índice de hidrofobicidade (Boatright, Hettiarachchy, 1995), que, para os hidrolisados de caseína nas $L I$, foi calculado pela subtração do valor do índice de hidrofobicidade de $L B$ daquele encontrado em $L I$.

\section{Análise sensorial}

O modelo descrito por Babiker et al. (1996a) foi usado para avaliar o sabor amargo das amostras. Volume de 3,5 mL de soluções de $H p$ e de $I L$ (contendo $1 \%$ de hidrolisado) foi usado neste teste. Cada amostra foi dividida em seis partes, que foram servidas, ao acaso, aos provadores. As amostras foram testadas a $25{ }^{\circ} \mathrm{C}$, em um ambiente uniformemente iluminado, por seis membros de um painel selecionado de um grupo de alunos e membros do Departamento de Alimentos, da Faculdade de Farmácia da UFMG. Treinamento inicial foi feito com os panelistas, que foram selecionados segundo o seu interesse em participar, sua habilidade gustativa, a aceitação pelo produto e sua capacidade em compreender os procedimentos do teste, de acordo com o método descrito por Paes Chaves e Spoesser (1986). A intensidade do amargor foi estimada utilizando-se uma escala estruturada em seis pontos, empregando-se solução de cafeína (zero a $1 \mathrm{mg} / \mathrm{mL}$ ) como controle. Água fresca foi fornecida para limpar o palato e evitar interferências entre cada degustação.

\section{Avaliação da oxidação lipídica}

A quantidade de substâncias reativas ao ácido 2tiobarbitúrico (thiobarbituric acid reactive substances TBARS) da $L I$ foi determinada de acordo com o método descrito por Rosmini et al. (1996), com algumas modificações, como a quantidade de amostra $(0,04 \mathrm{~g})$ e o volume dos reagentes ( $5 \mathrm{~mL}$ de água destilada, $5 \mathrm{~mL}$ ácido tricloroacético e $2,5 \mathrm{~mL}$ ácido tiobarbitúrico). A absorbância foi lida a $532 \mathrm{~nm}$ em espectrofotômetro (UVVIS - Cecil, modelo CE2041, Inglaterra). As amostras foram analisadas logo em seguida ao término da liofilização (tempo zero), e após 15, 30, 45 e 60 dias de armazenamento sob refrigeração a $4{ }^{\circ} \mathrm{C}$.

\section{Análise estatística}

Para avaliar o efeito do tempo de armazenamento sobre os valores de substâncias reativas ao ácido 2tiobarbitúrico (TBARS) da $L I$, foi adotado o delineamento experimental em parcelas subdivididas (no qual os diferentes valores de $L I$ foram as parcelas e os tempos de armazenamento as sub-parcelas). A análise de variância foi utilizada para determinar a existência de efeitos significativos ou interações entre os efeitos $(p<0,05)$. O teste de Duncan foi empregado para determinar diferenças entre as médias, para os efeitos que se mostraram significativos pelo teste de F (Pimentel-Gomes, 1990).

As diferenças entre as taxas de encapsulamento, a hidrofobicidade dos hidrolisados de caseína, antes $(H p)$ e após o encapsulamento $(L I)$, bem como as da análise sensorial foram determinadas por Análise de Variância (ANOVA). O teste de Duncan foi utilizado para determinar diferenças entre as médias (Pimentel-Gomes, 1990).

\section{RESULTADOS E DISCUSSÃO}

\section{Caracterização das lipoesferas}

A análise microscópica das lipoesferas contendo o 
(A)

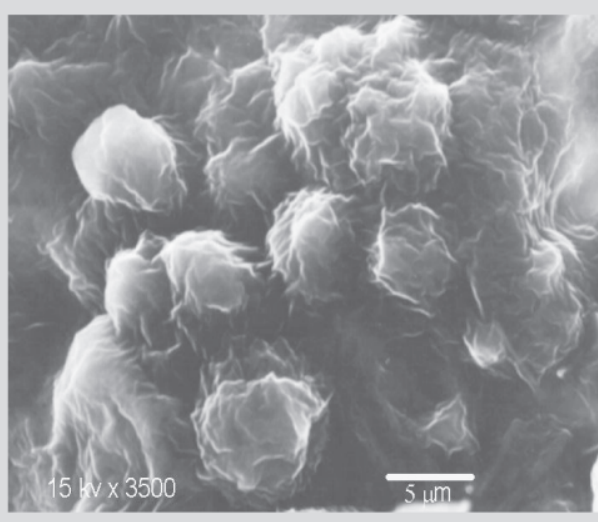

(B)

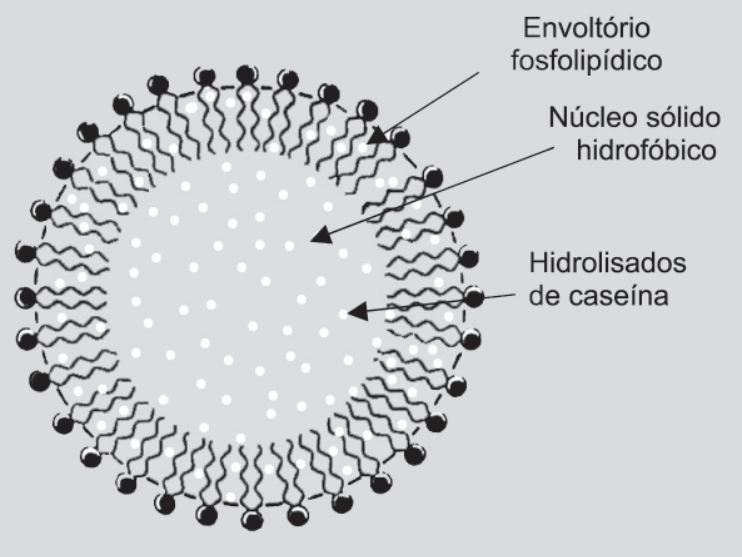

FIGURA 2 - (A) Fotomicrografia de uma típica formulação de lipoesferas contendo H2, através de microscopia eletrônica de varredura, ampliada 3500 vezes $($ barra $=5 \mu \mathrm{m})$. (B) Representação esquemática da partícula (Fonte: Benita, 1996).

hidrolisado $\mathrm{H} 2$ revelou morfologia esférica das mesmas, apresentando tamanho de partícula em torno de $3,8 \mu \mathrm{m}$ (Figura 1A). O sistema de lipoesferas investigado consiste de um núcleo sólido hidrofóbico de ácido esteárico contendo o hidrolisado de caseína, recoberto por uma superfície de fosfatidilcolina de soja, como esquematizado na Figura 2(B).

\section{Determinação da taxa de encapsulamento}

Para todos os hidrolisados estudados, a área do pico negativo "a" foi a escolhida para se traçar a curva padrão, visto que este parâmetro apresentou o maior coeficiente de correlação. A título de exemplo, na Figura 3, está apresentada a curva padrão obtida para o hidrolisado $\mathrm{H} 3$ na $L I$. As equações das retas e os coeficientes de correlação foram, respectivamente, para os hirolisados $\mathrm{H} 1, \mathrm{H} 2$ e H3: y = $39,155 \mathrm{x}-0,5592, \mathrm{r}^{2}=0,9967 ; \mathrm{y}=32,525 \mathrm{x}-0,1322, \mathrm{r}^{2}=$ 0,$9940 ; \mathrm{y}=28,384 \mathrm{x}-0,5077, \mathrm{r}^{2}=0,9964$.

$\mathrm{Na}$ Tabela II estão apresentadas as taxas de encapsulamento dos hidrolisados em lipoesferas. Nestas preparações, as taxas de encapsulamento variaram de 50 a $83 \%$.

Não foram encontrados dados na literatura com relação à medida da taxa de encapsulamento de hidrolisados protéicos em lipoesferas. Além disso, os dados disponíveis indicam que a EDS somente foi utilizada até o presente para a determinação desta taxa no caso de clordiazepóxido, brometo de clidínio e brometo de oxifenônio em formulações farmacêuticas (Funasaki et al., 1999; Toral et al., 1999). O emprego desta técnica no presente trabalho justifica-se pelo fato de já ter sido utilizada na análise de hidrolisados de caseína, tendo apresentado resultados de grande interesse prático (Silvestre et al., 1993). Outros autores também utilizaram a EDS para análise de diversas proteínas e ressaltaram a sua eficiência para separar bandas superpostas no espectro UV-V, bem como sua simplicidade, rapidez, sensibilidade e precisão (Ichikawa, Terada, 1981; Ragone et al, 1984; Ferre, Shanon, 2001).

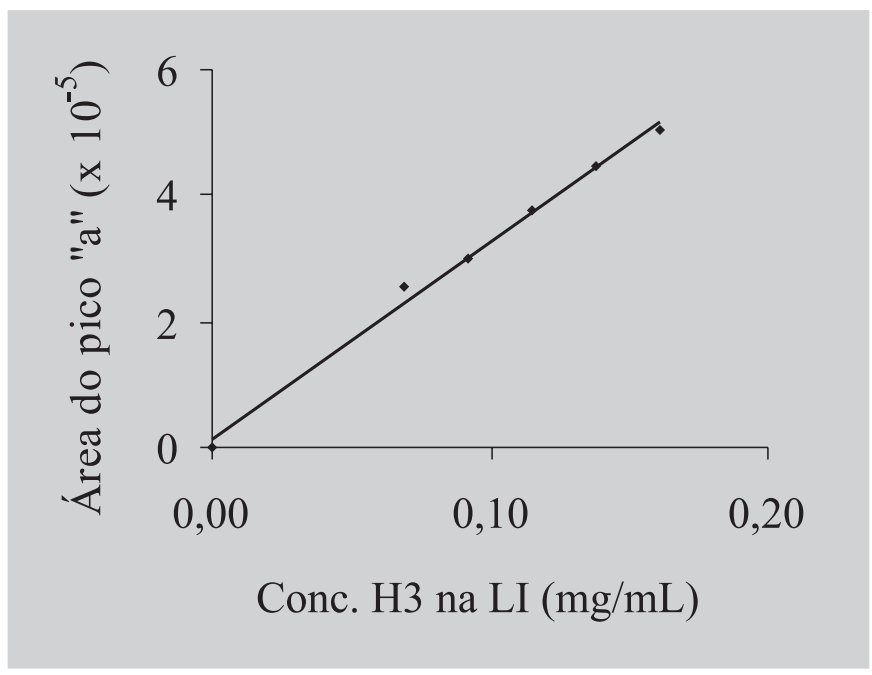

FIGURA 3 - Correlação entre a área do pico negativo "a" (FIGURA 1B), obtida no espectro de derivada segunda, e a concentração do hidrolisado $\mathrm{H} 3$ na $L I$. 
TABELA II - Taxa de encapsulamento de diferentes hidrolisados de caseína em lipoesferas

\begin{tabular}{ccccc}
\hline Amostra* & \multicolumn{2}{c}{ Concentração $(\mathrm{mg}$ hidrolisado/mL)** } & & Taxa de encapsulamento (\%) \\
\cline { 2 - 3 } & $H t$ & $H s$ & $H e$ & \\
\hline$L I-\mathrm{H} 1$ & $1,38 \times 10^{-1}$ & $6,92 \times 10^{-2}$ & $6,88 \times 10^{-2}$ & $50^{\mathrm{c}}$ \\
$L I-\mathrm{H} 2$ & $1,23 \times 10^{-1}$ & $4,81 \times 10^{-2}$ & $7,49 \times 10^{-2}$ & $61^{\mathrm{b}}$ \\
$L I-\mathrm{H} 3$ & $1,38 \times 10^{-1}$ & $2,33 \times 10^{-2}$ & $11,47 \times 10^{-2}$ & $83^{\mathrm{a}}$ \\
\hline
\end{tabular}

* Lipoesferas integrais contendo os hidrolisados $\mathrm{H} 1, \mathrm{H} 2$ e H3, respectivamente. **Ht: concentração de hidrolisado nas lipoesferas integrais; $H s$ : concentração de hidrolisado no sobrenadante; He: concentração de hidrolisado encapsulado. Os valores representam a média de triplicatas. Médias indicadas por letras iguais não diferem entre si a 5\% de probabilidade.

\section{Avaliação da hidrofobicidade}

Na Tabela III estão apresentados os índices de hidrofobicidade das soluções de $H p$ e de $L I$.

TABELA III - Índice de hidrofobicidade dos hidrolisados de caseína antes $(H p)$ e após o encapsulamento em lipoesferas (Ht)

\begin{tabular}{lll}
\hline & \multicolumn{2}{c}{ Hidrofobicidade } \\
& $H p$ & $H t$ \\
\hline $\mathrm{H} 1$ & $5272^{\mathrm{a} / 1}$ & $2721^{\mathrm{x} / 2}$ \\
$\mathrm{H} 2$ & $5409^{\mathrm{a} / 1}$ & $2864^{\mathrm{x} / 2}$ \\
$\mathrm{H} 3$ & $5649^{\mathrm{b} / 1}$ & $2009^{\mathrm{y} / 2}$ \\
\hline
\end{tabular}

* Os valores obtidos representam a média de triplicatas. Médias indicadas por letras iguais não diferem entre si a $5 \%$ de probabilidade, na mesma coluna. Médias indicadas por números iguais não diferem entre si a $5 \%$ de probabilidade, na mesma linha.

Observa-se que o encapsulamento dos hidrolisados em lipoesferas contribuiu para reduzir a hidrofobicidade das três amostras analisadas. As reduções foram de 52\%, $53 \%$ e $36 \%$ para $\mathrm{H} 1, \mathrm{H} 2$ e $\mathrm{H} 3$, respectivamente.

Ressalta-se, ainda, que o hidrolisado $\mathrm{H} 3$, para o qual se obteve o índice mais elevado de hidrofobicidade, foi também o que apresentou maior taxa de encapsulamento (Tabela II). Isto pode ser explicado pelo fato de que, como mostrado na Figura 1B, o encapsulamento do hidrolisado em lipoesferas ocorre no núcleo hidrofóbico e entre as cadeias apolares do envoltório fosfolipídico. Assim sendo, a quantidade encapsulada de hidrolisado estará diretamente associada ao seu teor de grupos hidrofóbicos.

\section{Avaliação sensorial}

Os resultados da análise sensorial, apresentados na Figura 4, indicam que o encapsulamento em lipoesferas foi eficiente na redução do sabor amargo dos três hidrolisados de caseína. Este vantajoso decréscimo do amargor foi de $32 \%$ para $\mathrm{H} 1,38$ para $\mathrm{H} 2$ e $26 \%$ para $\mathrm{H} 3$.

Lynn et al. (1997), empregando 3 colunas de adsorção hidrofóbica (C18, C8 e resina fenólica) para remover o amargor de hidrolisados enzimáticos de caseína, mostraram que a coluna $\mathrm{C} 8$ foi a mais eficiente, não sendo possível, entretanto, eliminar completamente o amargor das amostras, como obtido no presente trabalho.

Vários trabalhos na literatura relacionam a presença de grupos hidrofóbicos em peptídeos com a sensação de gosto amargo, relatando que, quanto mais elevada for a hidrofobicidade maior será o grau de amargor (Yeom et al., 1995; Babiker et al., 1996a, b). Os resultados obtidos para análise sensorial dos hidrolisados de caseína encapsulados em lipoesferas, estão de acordo com aqueles observados nos estudo de hidrofobicidade, mostrando que a redução deste último contribui com a diminuição do sabor amargo. Entretanto, no presente trabalho, apesar do hidrolisado $\mathrm{H} 3$ ter mostrado um índice de hidrofobicidade superior ao do $\mathrm{H} 1$ e do H2, não se observaram diferenças significativas no amargor entre as amostras analisadas. Uma explicação para este resultado poderia se basear no fato de que a maior hidrofobicidade obtida para o $\mathrm{H} 3$ não ter sido suficientemente importante para influenciar na percepção do sabor amargo, uma vez que os aminoácidos hidrofóbicos, estando ligados ao núcleo sólido no interior das lipoesferas, poderiam estar impedidos de interagir com as papilas gustativas. Além disso, a adstringência dos fosfolípides pode ter influenciado na capacidade dos provadores em identificar o amargor das amostras relacionada com a interferência do sabor adstringente dos fosfolípides presentes na formulação. 


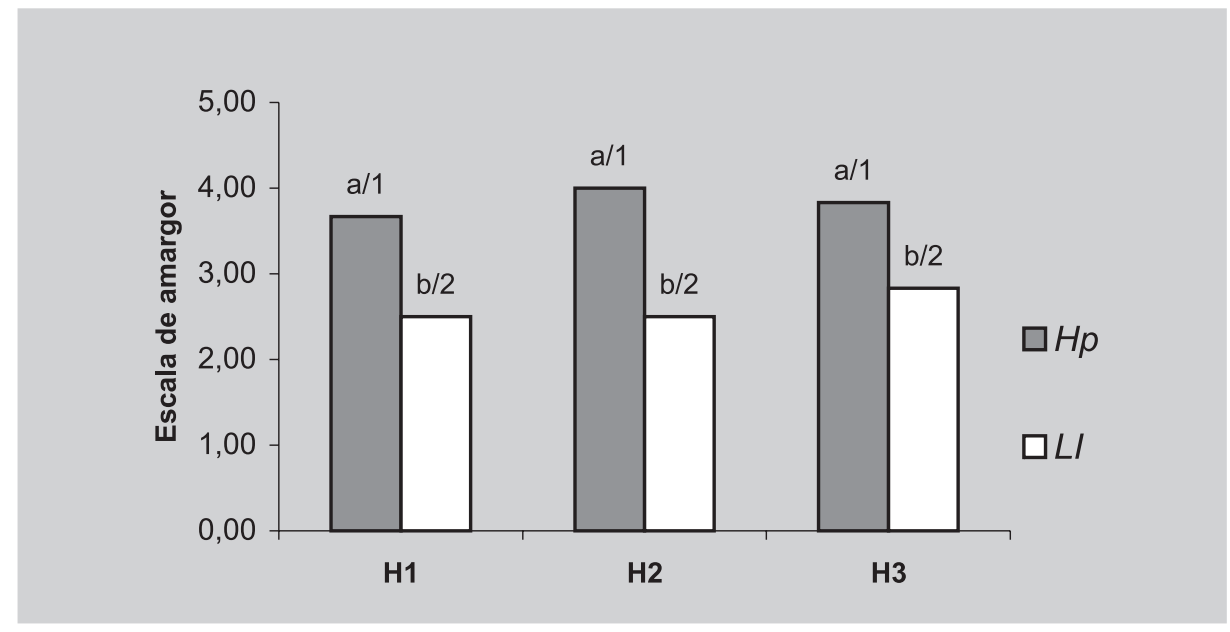

FIGURA 4 - Avaliação sensorial dos hidrolisados de caseína H1, H2 e H3, antes $(H p)$ e após o encapsulamento em lipoesferas $(L I)$. Médias indicadas por letras iguais não diferem entre si a 5\% de probabilidade na comparação de um mesmo hidrolisado, antes e após o encapsulamento. Médias indicadas por números iguais não diferem entre si a 5\% de probabilidade na comparação de diferentes hidrolisados, antes e após o encapsulamento (lipoesferas).

\section{Avaliação da oxidação lipídica}

Os dados relativos à oxidação lipídica da $L I$, em função do tempo, estão apresentados na Figura 5. Observa-se que não houve diferença significativa entre as amostras analisadas, e nem ao longo do período de estudo para cada amostra, demonstrando a estabilidade química das lipoesferas. Esta característica poderia contribuir para a retenção do material encapsulado durante o período de estocagem. Não foram encontrados estudos na literatura sobre a evolução da oxidação lipídica em lipoesferas.

Finalmente, é importante ressaltar que também não foram encontrados relatos na literatura abordando o emprego de lipoesferas na área de alimentos, bem como o encapsulamento de hidrolisados enzimáticos de proteínas.

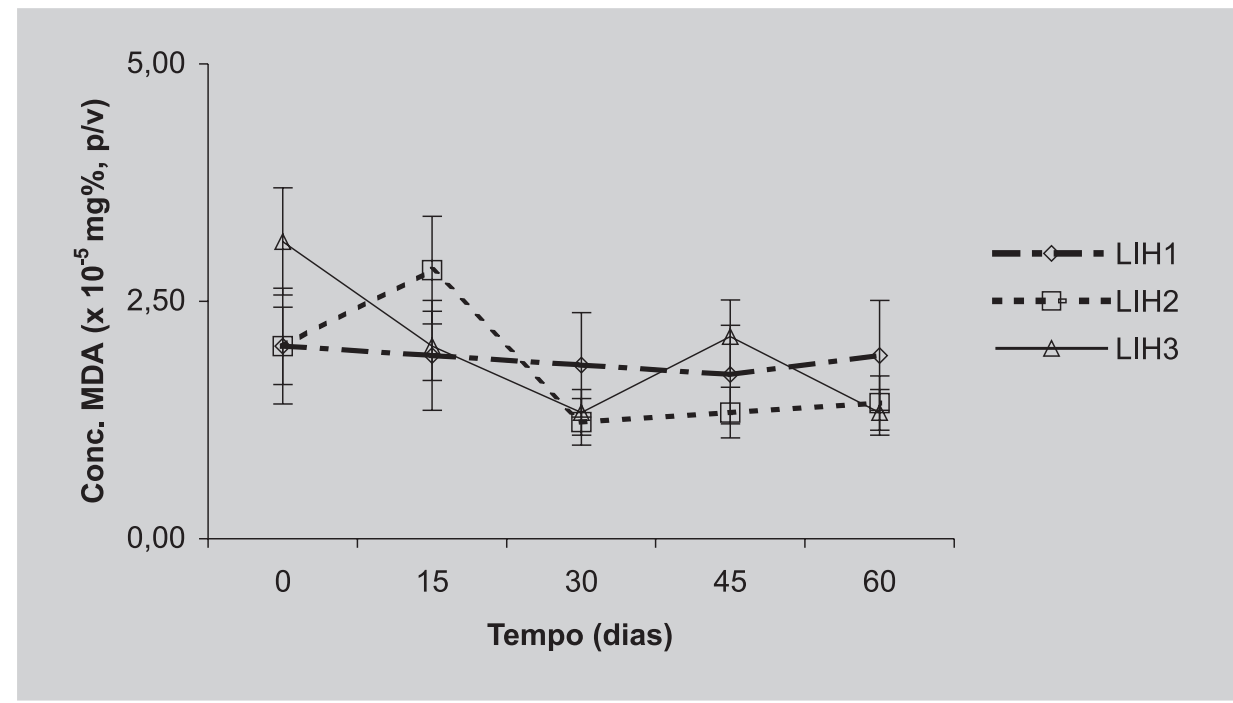

FIGURA 5 - Efeito do tempo de armazenamento sobre os valores de substâncias reativas ao ácido 2-tiobarbitúrico (TBARS) das lipoesferas contendo diferentes hidrolisados. LIH1 = lipoesferas com hidrolisado H1; LIH2 = lipoesferas com hidrolisado H2; LIH3 = lipoesferas com hidrolisado H3; MDA = malonaldeído. Os resultados representam a média das triplicatas. 


\section{CONCLUSÃO}

O microencapsulamento em lipoesferas mostrou ser uma tecnologia eficiente para reduzir a hidrofobicidade e o sabor amargo de hidrolisados de caseína obtidos pela ação da papaína, devendo ser testado em larga escala. A medida da oxidação lipídica destas microcápsulas revelou sua boa estabilidade química por um período de até 60 dias. Os resultados apresentados pela espectrofotometria derivada segunda (EDS) indicaram que este método pode ser empregado para avaliação indireta da taxa de encapsulamento destas amostras.

\section{AGRADECIMENTOS}

Os autores agradecem à CAPES, CNPq e FAPEMIG pelo apoio financeiro a este trabalho, na forma de bolsas de estudo ou de verba para a pesquisa.

\section{ABSTRACT \\ Microencapsulation of casein hidrolysates in lipospheres for debittering flavor: physical- chemistry and sensorial evaluation}

In several studies the nutritional value of enzymatic protein hydrolysates has been related to their small peptide contents, especially di- and tripeptides. However, a disadvantage found in the enzymatic process is the development of a bitter taste, which is one of the main obstacles for using the hydrolysates in dietetic formulations and also seems to be associated to the exposition of buried hydrophobic groups. The methods proposed in the literature to solve this problem show some disadvantages, like the reduction of the nutritional value of these preparations. In this work, a new methodology based on the encapsulation in lipospheres was developed, in order to debittering casein hidrolysates obtained by using papain. The second derivative spectrophotometry $(S D S)$ was used for the first time, for measuring the entrapment efficiency of protein hidrolysates and the results were around $66 \%$. This microencapsulation system showed to be an efficient technology to reduce the hydrophobicity and the bitter taste of casein hidrolysates. The scanning electronic microscopy revealed the spherical morphology of this microcapsules, and the measurement of the lipid oxidation indicated a good chemical stability in a period of time up to 60 days.
UNITERMS: Protein hidroliysates. Debittering flavor. Encapsulation in lipospheres. Electronic microscopia. Second derivative spectrophotometry. Llipid oxidation.

\section{REFERÊNCIAS BIBLIOGRÁFICAS}

ADLER-NISSEN, J. Procesamiento enzimatico de las proteinas alimenticias. Alimentos, v.6, p.29-33, 1981.

BABIKER, E. F. E., FUJISAWA, N., MATSUDOMI, N., KATO, A. Improvement in the functional properties of gluten by protease digestion or acid hydrolysis followed by microbial transglutaminase treatment. J. Agric. Food Chem., v. 44, n.12, p. 3746-3750, 1996a.

BABIKER, E. F. E., KHAN, M.A. S. N., MATSUDOMI, N., KATO, A. Polymerization of soy protein digests by microbial transglutaminase for improvement of the functional properties. Food Res. Int., v. 29, n. 7, p. 627 $634,1996 b$.

BENITA, S. Microencapsulation Methods and industrial applications. New York: Marcel Dekker, 1996. 640 p.

BOATRIGHT, W. L., HETTIARACHCHY, N. S. Soy protein isolate solubility and surface hidrophobicity as affected by antioxidants. J. Food Sci, v.60, n. 60, p.798800, 1995.

BOZA, J. J., MARTÍNEZ-AUGUSTIN, O., GIL, A. Nutritional and antigenic characterization of an enzymatic whey protein hydrolysate. J. Agric. Food Chem., v. 43, n.4, p.872-875, 1995.

CHATAUD, J., DESREUMEUX, S., CARTWRIGHT, T. Procédé de fabrication d'un hydrolysat enzymatique de protéines riche en di- et tri-peptides, utilisable notamment en nutrition artificielle et en dietétique. Laboratório Roger Bellon, Neuilly-sur-Seine-FR. A23J3/00. FR87402837.6, 0.274946A1. 14/12/1987, 20/07/1988.

DOMB, A. J. Lipospheres for controlled delivery of substances. U.S. Patent 5,188,837, Fev. 1993a. Disponível em: http://www.patents.ibm.com. Acesso em: 14 out. 1999.

DOMB, A. J. Sustained release formulations of insect repellent. U.S. Patent 5,221,535, Jun. 1993b. Disponível em: http://www.patents.ibm.com. Acesso em: 14 out. 1999. 
FERRE, M. A., SHANNON, R. D. Evaluation of a second derivative UV/visible spectroscopy technique for nitrate and total nitrogen analysis of wastewater samples. Wat. Res., v.35, n. 1, p. 327-332, 2001.

FRFKJAER, S. Use of hydrolysates for protein supplementation. Food Techn., v.48, n.10, p.86-88, 1994.

FREITAS, O., PADOVAN, G. J., VILELA, L., SANTOS, J. E., DUTRA DE OLIVEIRA, J. E., GREENE, L. J. Characterization of protein hydrolysates prepared for enteral nutrition. J. Agric. Food Chem., v.41, n.8, p.14321438, 1993.

FUNASAKI, N., KAWAGUCHI, R., HADA, S., NEYA, S. Ultraviolet spectroscopic estimation of microenvironments and bitter taste of oxyphenonium bromide in cyclodextrins solutions. Int. J. Pharm. Sci., v. 88, n. 8, p. 759-762, 1999.

GONZÁLEZ-TELLO, P., CAMACHO, F., JURADO, E., PAÉZ, M. P., GUADIX, E. M. Enzymatic hydrolysis of whey proteins. II. Molecular-weight range. Biotech. Bioeng., v.44, n.4, p.529-532, 1994.

ICHIKAWA, T., TERADA, H. Effect of dodecyl sulfate on the spectral properties of phenhylalanine residues in serum albumin detected by second derivative spectrophotometry. Biochim. Biophys. Acta, v. 671, p. 3337, 1981.

LIN, S-B, NELLES, L. P., CORDLE, C. T., THOMAS, R. L. Debittering casein hydrolysates with octadecyl-siloxane (C18) columns. J. Food Sci., v. 62, n. 4, p. 665-670, 1997.

KIM, .H. H., BAIANU, I. C. Novel liposome microencapsulation techniques for food applications. Trends Food Sci. Technol., p. 55-61, 1991.

KRISTINSSON, H. G., RASCO, B. A. Fish protein hydrolysates: production, biochemical and functional properties. Crit. Rev. Food. Sci. Nutrit., v. 40, n. 1, p. 43$81,2000$.

MINAGAWA, E., KAMINOGAWA, S., TSUKASAKI, F., YAMAUCHI. K. Debittering mechanism in bitter peptides of enzymatic hydrolysates from milk casein by aminopeptidase T. J. Food Sci., v.54, p.1225-1229, 1989.
PAES CHAVES, J. B., SPROESSER, R. L. Práticas de laboratório de análise sensorial de alimentos e bebidas. Viçosa: UFV, 1991.p. 97.

PEDERSEN, B. Removing bitterness from protein hydrolysates. Food Technol., v. 48, n.10, p.96-99, 1994.

PIMENTEL-GOMES, F. Curso de estatística experimental. 13. ed. Piracicaba: Nobel, 1990. 476p.

RAGONE, R., COLONNA, G., BALESTRIERI, C., SERVILLO, L., IRACE, G. Determination of tyrosine exposure in proteins by second-derivative spectroscopy. Biochem., v. 23, p. 1871-1875, 1984.

ROSMINI, M. R., PERLO, F., PÉREZ-ALVAREZ, J. A., PAGÁN-MORENO, M. J., GAGO-GAGO, A., LÓPEZ-SANTOVEÑA, F., ARANDA-CATALÁ, V. TBA test by na extractive method applied to paté. Meat Sci., v. 42, p. 103-110, 1996.

SGARBIERI, V. C. Proteína em alimentos protéicospropriedades-degradações-modificações. São Paulo: Varela, 1996. p. 517.

SHAHIDI, F., HAN, X. Q. Encapsulation of food ingredients. Crit. Rev. Food Sci. Nutr., v.33, p. 501-547, 1993.

SILVESTRE, M. P. C., DAUPHIN, C, HAMON, M. Application of UV absorbance and second-derivative spectrophotometry for analysing casein hydrolysates. Anal. Chim. Acta, v. 282, p. 603-612, 1993.

SMITHERS, G. W., BRADFORD, R. S. New casein products: fresh opportunities for the dairy industry. Food Res. Quart., v.51, n.1, p.92-98, 1991.

STEVENSON, D. E., OFMAN, D. J., MORGAN, K. R., STANLEY, R. A. Protease-catalyzed condensation of peptides as a potential means to reduce the bitter taste of hydrophobic peptides found in protein hydrolysates. Enz. Mic. Techn., v.22, p.100-110, 1998.

SYNOWIECKI, J., JAGIELKA, R., SHAHIDI, F. Preparation of hydrolysates from bovine red blood cells and their debittering following plastein reaction. Food Chem., v.57, n.3, p.435-439, 1996. 
TORAL, M. I., RICHTER, P., LARA, N., JAQUE, R., SOTO, C., SAAVEDRA, M. Simultaneous determination of chlordiazepoxide and clidinium bromide in pharmaceutical formulations by derivative spectrophotometry. Int. J. Pharm., v. 189, n. 1, p. 67-74, 1999.

UTREJA, S., KHOPADE, A. J., JAIN, N. K. Lipoproteinmimicking biovectorized systems for methotrexate delivery. Pharm. Acta Helvetiae, v. 73, p. 275-279, 1999.
YEOM, H. W., KIM, K. S., RHEE, J. S. Soy protein hidrolysate debittering by lysine-acetylation. J. Food Sci., v.59, n. 5, p.1123-1126, 1994.

Recebido para publicação em 12 de junho de 2002. 